Research/Technical Notes

\title{
Depolymerized Chitosan: A Novel Milk Protein Stabilizer
}

\author{
Department of Chemistry, National Institute of Technology, Agartala, India \\ Email address: \\ srijitabasumallick@gmail.com (S. Basumallick),tkmisra70@yahoo.com (T. K. Mishra)
}

Manna Majumder, Rupasree Chudhury, Tarun Kumar Mishra, Srijita Basumallick*

\section{To cite this article:}

Manna Majumder, Rupasree Chudhury, Tarun Kumar Mishra, Srijita Basumallick. Depolymerized Chitosan: A Novel Milk Protein Stabilizer. Advances in Bioscience and Bioengineering. Vol. 3, No. 6, 2015, pp. 56-58. doi: 10.11648/j.abb.20150306.11

\begin{abstract}
Chitosan is a bio-degradable polymer obtained easily from natural polymer chitin which is abundantly found in the outer hard skeleton of shellfishes like crab, lobster, and shrimp. It has immense pharmaceutical uses as anti-oxidant and anti-bacterial material. We have presented here one-step hydrothermal method of preparation of depolymerized water dispersible chitosan particles using citric acid as a depolymerizer and ionic cross linker and their stabilizing effect on cow milk proteins from fluorimetric and differential scanning calorimetric studies. We report for the first time protein stabilizing effect of depolymerized chitosan from thermal denaturation of milk protein. This has been explained by carbohydrate like structural skeleton of chitosan.
\end{abstract}

Keywords: Chitosan, Milk Protein, Denaturation

\section{Introduction}

Chitosan is a biodegradable, biocompatible polymer derived from natural polymer chitin and used extensively in drug delivery $[1,2]$, gene delivery $[3,4]$ tissue engineering $[5$, $6]$, textile industry and food packaging. It is non- toxic, nonimmunogenic and non- carcinogenic [7-10]. It is widely used as antibacterial, antioxidant agents and as medicine for obesity and high cholesterol treatment. The $-\mathrm{NH}_{3}{ }^{+}$group of chitosan can bind with negatively charged biological molecule [11]. Thus, mucoadhesive property and platelet aggregation are due to interactions [12-15] of positively charged CS with negatively charged mucous. But chitosan is insoluble in biological $\mathrm{pH}$. It is important to make highly waterdispersible chitosan at biological $\mathrm{pH}$. Chitosan is soluble in acidic $\mathrm{pH}(\mathrm{pH}<5.0)$ due to protonation of amino groups present in the polymer chain. We have followed our earlier protocol [16] of making water- dispersible chitosan colloid particles but modified using citric acid as a depolymerizer of polymer chain and ionic cross linker.

The molecular structural unit of this bio-polymer is unique. On one hand, it contains sugar like skeleton and on the other hand, it has urea-like $\left(-\mathrm{NH}_{2}-\mathrm{C}=\mathrm{O}\right)$ group. It is well-known sugar and poly-ols stabilize native conformation of protein from denaturing effect of heat and other denaturing agents and urea enhance denaturation. So, it will be of particular interest to study the effect of chitosan on the folding-unfolding behaviour of proteins.

We have selected milk protein (mainly, casein and whey proteins) obtained by coagulation of milk proteins by citric acid. Heat denaturation of milk protein is a subject of wide interest because of its nutritional value.

\section{Experimental}

$300 \mathrm{mg}$ of low molecular weight chitosan (Himedia, CAS no 9012-76-4, DD > 75\%) was weighed out in a $50 \mathrm{ml}$ centrifuge tube. $300 \mathrm{mg}$ of citric acid (Mark) was added to the solid chitosan powder followed by dissolving the mixture in $30 \mathrm{ml}$ DI water under brief vortex. The chitosan particles were not dissolved completely and formed semi-fluid gel-like material. The mixture was transferred to a Teflon taped $50 \mathrm{ml}$ hydrothermal container and kept in pre heated oven at $150^{\circ} \mathrm{C}$ for 90 minutes followed by cooling it at room temperature. The final product was transparent fluid at $\mathrm{pH}$ 3.0. This fluid was filtered through 0.45 um filter and was dialyzed by dialysis tube with $3.5 \mathrm{~K}$ Da Mwt cut off, against DI water and finally $\mathrm{pH}$ was adjusted to 6.5 to obtain highly water dispersible colloidal chitosan particles.

Cow milk $100 \mathrm{ml}$ was taken in a $250 \mathrm{ml}$ Beaker, citric acid solution $1 \%$ was added gradually to obtain coagulated milk protein (casein + whey), which was dialyzed using a cloth bag against DI water, pressed to remove excess water and dried in cold air. 
$200 \mathrm{mg}$ of this air dry solid protein was dispersed in $20 \mathrm{ml}$ of DI water by sonication to obtain a colloidal dispersion of milk protein (stock solution). This stock solution was further diluted further for fluorescence study.

\section{Result and Discussion}

The depolymerization of CS is confirmed by determination of viscosity average molecular mass in $1 \%$ Acetic acid, with $\mathrm{K}$ and $\alpha$ values $4.74 \times 10^{-5} \mathrm{dLg}^{-1}$ and 0.72 respectively [17]. The average molecular mass of the depolymerized sample has been found to decrease by $45 \%$ of the starting material. Unlike the starting material, this depolymerized sample gets water dispersible easily.
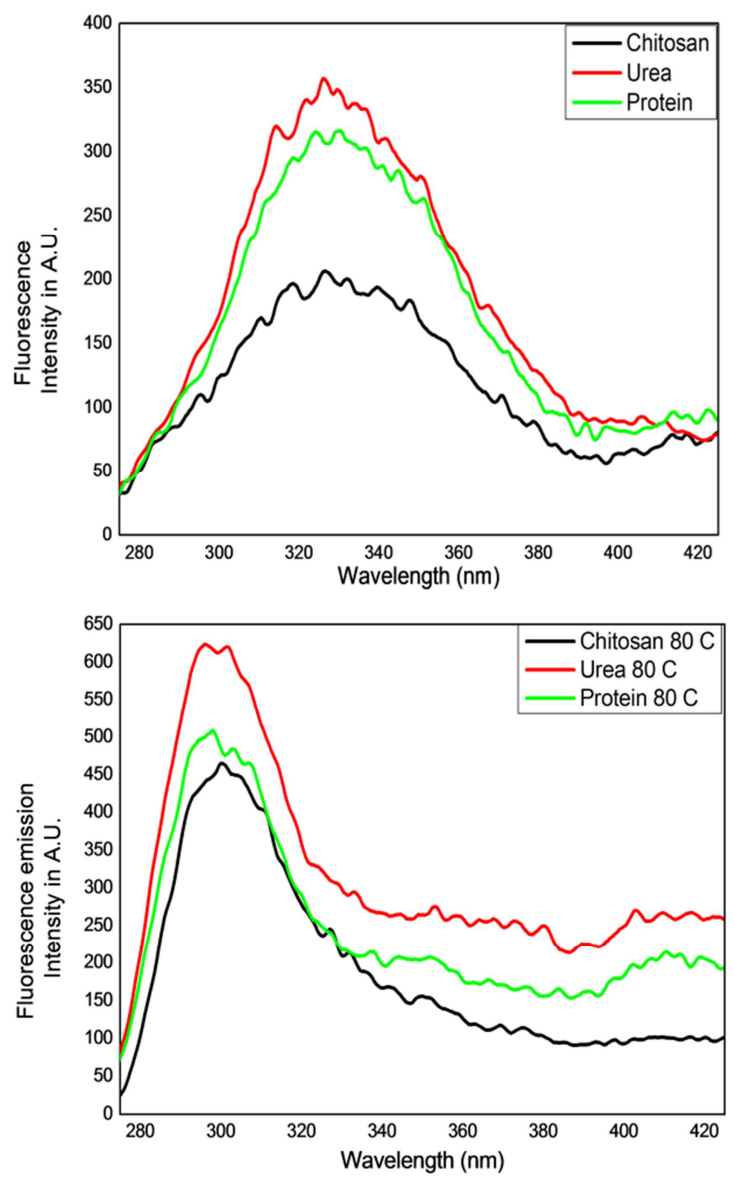

Fig. 1. Fluorescence spectra (left) of dilute aqueous dispersion of milk protein (green) and in the presence of urea $(4 \mathrm{~m}$, red) and depolymerized CS $(10 \%$, black) at $30^{\circ} \mathrm{C}$. Similar spectra (right) at $80^{\circ} \mathrm{C}$.

Figure 1, shows the fluorescence emission spectra of dilute aqueous milk protein (whey protein incorporated ceresin micelle, green line) at $\sim 330 \mathrm{~nm}$ when excited at $220 \mathrm{~nm}$. Similar emission spectra of milk protein in the presence of depolymerized CS (10\% w/v, black line) and urea (4M, red line) are also shown. Intrinsic fluorescence due to tryptophan residue is a perfect indicator of protein denaturation [18]. Tryptophan emits around $330 \mathrm{~nm}$ and its fluorescence quantum yield increases with the degree of denaturation. It is known that the protein denaturation, as well as agglomeration, may happen simultaneously. The agglomeration can be measured by the blue shift of fluorescence coming from tryptophan. The native protein fluorescence is shown at $\sim 330$ $\mathrm{nm}$ of tryptophan but it shifts to $300 \mathrm{~nm}$ when agglomerated [18]. Urea is a common denaturant for protein. It works by breaking hydrophobic hydration shell or by binding directly to the protein to break intra molecular hydrogen bond. On the other hand, glycerol, polyols and sugar acts as stabilizer of folded conformation of protein from denaturing effects of heat and other agents. Chitosan has both amine group and carbohydrate like skeleton. So it may acts as a stabilizer of folded conformation of protein or as a denaturant like urea. Due to unfolding, more tryptophan residues are exposed to the aqueous environment resulting enhancement of fluorescence emission intensity, as is expected in the presence of a denaturing agent. Similarly, decrease in fluorescence intensity is observed in the presence of a protein stabilizing agent.

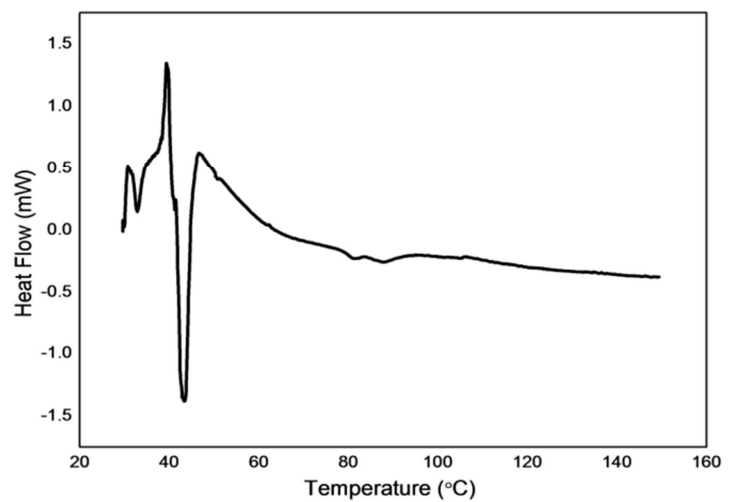

Fig. 2. DSC curve of Chitosan-milk protein composite at a scan rate of $1^{\circ} \mathrm{C}$ per minutes.

But complication arises due to the aggregation of protein in the presence of these agents. It is well known in the presence of denaturing agent like urea, protein-protein aggregation occurs. Similarly stabilizing agent acts as anti coagulant due to compact structure of protein. We have carefully eliminated this problem using a dilute solution of protein. Thus, fluorescence spectra of milk protein in the presence of depolymerized CS and urea at two different temperatures $30^{\circ} \mathrm{C}$ and $80^{\circ} \mathrm{C}$ primarily indicate depolymerized CS acts as protein stabilizer in dilute aqueous dispersions of milk proteins. Poly-ols and sugar are well known [19] protein stabilizers; chitosan has also carbohydrate like structural skeleton, possibly, owing to the presence of such a skeleton attached to -OH groups, depolymerized CS acts as protein stabilizer. The mechanisms of protein stabilizing activity of poly-ols and sugar are not yet clearly known [20]. However, specific interaction mechanism and interactions through alteration of water structure [21] around protein have been proposed. Recently, Ben-Naim [21] has proposed a new approach explaining heat and cold denaturation of the protein. This hypothesis is based on solvent-mediated interaction of a denaturing agent with the hydrophilic sites of the protein.

Different experimental approaches have also been examined. Preparation of protein-stabilizing agent complexes 
and study of their XRD and DSC [22] have been reported. We have also prepared this milk protein - depolymerized CS composite at slightly alkaline $(8.5) \mathrm{pH}$ at room temperature to facilitate electro-static interactions and studied their DSC (Fig. 2.). It is clear from the DSC curve that conformation changes occur at a low temperature near $45^{\circ} \mathrm{C}$, other researchers [23] have also observed peaks at this temperature. Close scrutiny of the DSC curve indicates two shoulder peaks at 81 and $88^{\circ} \mathrm{C}$. Prominent shoulder peaks for denaturation of beta-lacto- and alfa -lactalbumin in whey protein and casein protein mixture like the present one have been observed at 68 and $73^{\circ} \mathrm{C}$ [23]. Here we observe an increased in denaturation temperatures of milk proteins in the presence of depolymerized CS, indicating milk protein stabilizing activity of depolymerized CS.

\section{Conclusions}

We have de-polymerized chitosan to water dispersible chitosan by one step method using citric acid as a depolymerized agent. We have demonstrated for the first time from simple fluorescence study that this depolymerized CS acts as milk protein stabilizer. This has been explained in terms of the presence of carbohydrate like skeleton in its structure.

\section{Acknowledgement}

We are thankful to the HOD, Chemistry, National Institute of Technology for providing infra structural support for this research.

\section{References}

[1] L. Hu, Y. Sun, Y. Wu, Advances in chitosan-based drug delivery vehicles, Nanoscale. 5(8) (2013) 3103-11.

[2] R. Susana, D. Marita, R. L. Carmen, G. Ana, Biocompatibility of Chitosan Carriers with Application in Drug Delivery, J. Funct. Biomater. 3 (2012) 615-41.

[3] M. Koping-Hoggard, I. Tubulekas, H. Guan, K. Edwards, M. Nilsson, K. M. Varum, P. Artursson, Chitosan as a nonviral gene delivery system. Structure-property relationships and characteristics compared with polyethylenimine in vitro and after lung administration in vivo, Gene therapy. 8(14) (2001) 1108-21.

[4] P. Erbacher, S. M. Zou, T. Bettinger, A. M. Steffan, J. S. Remy, Chitosan-based vector/DNA complexes for gene delivery: Biophysical characteristics and transfection ability, Pharmaceutical Research. 15(9) (1998) 1332-9.

[5] R. A. A. Muzzarelli, F. Greco, A. Busilacchi, V. Sollazzo, A. Gigante, Chitosan, hyaluronan and chondroitin sulfate in tissue engineering for cartilage regeneration: A review, Carbohydrate Polymers. 89 (3) (2012) 723-39.

[6] J. K. F. Suh, H. W. T. Matthew, Application of chitosan-based polysaccharide biomaterials in cartilage tissue engineering: a review, Biomaterials. 21(24) (2000) 2589-98.

[7] M. N. Kumar, R. A. A. Muzzarelli, C. Muzzarelli, H. Sashiwa, A. J. Domb, Chitosan Chemistry and Pharmaceutical Perspectives, Chemical Reviews. 104(12) (2004) 6017-84.
[8] L. Illum, Chitosan and its use as a pharmaceutical excipient, Pharmaceutical Research. 15(9) (1998) 1326-31.

[9] O. Felt, P. Buri, R. Gurny, Chitosan: A unique polysaccharide for drug delivery, Drug Development and Industrial Pharmacy. 24(11) (1998) 979-93.

[10] K. S. Nam, M. K. Kim, Y. H. Shon, Chemopreventive effect of chitosan oligosaccharide against colon carcinogenesis, Journal of Microbiology and Biotechnology. 17 (9) (2007) 1546-9.

[11] S. Hirano, M. Zhang, M. Nakagawa, T. Miyata, Wet spun chitosan-collagen fibers, their chemical N-modifications, and blood compatibility, Biomaterials. 21 (10) (2000) 997-1003.

[12] D. A. Patil, G. B. Patil, P. K. Deshmukh, V. S. Belgamwar, R. A. Fursule, Chitosan coated mucoadhesive multiparticulate drug delivery system for gliclazide, Asian Journal of Pharmaceutical and Clinical Research. 2(2) (2009) 62-8.

[13] Y. Okamoto, R. Yano, K. Miyatake, I. Tomohiro, Y. Shigemasa Y, S. Minami, Effects of chitin and chitosan on blood coagulation, Carbohydrate Polymers. 53 (3) (2003) 337-42.

[14] A. M. Qandil, A. A. Obaidat, M. A. M. Ali, B. M. Al-Taani, B. M. Tashtoush, N. D. Al-Jbour, M. M. Al Remawi, K. A. Al-Sou'od, A. A. Badwan, Investigation of the Interactions in Complexes of Low Molecular Weight Chitosan with Ibuprofen, Journal of Solution Chemistry. 38 (6) (2009) 695-712.

[15] M. Roldo, M. Hornof, P. Caliceti, A. Bernkop-Schnurch, Mucoadhesive thiolated chitosans as platforms for oral controlled drug delivery: synthesis and in vitro evaluation, European Journal of Pharmaceutics and Biopharmaceutics. 57 (1) (2004) 115-21.

[16] S. Basumallick, S. Santra, Chitosan coated copper-oxide nano particles: a novel electro-catalyst for $\mathrm{CO}_{2}$ reduction, RSC Advance. 4 (2014) 63685-90.

[17] D. G. Rao, Studies on Viscosity-Molecular Weight Relationship of Chitosan Solutions, Journal of Food Science and Technology (India). 30 (1) (1993) 66-7.

[18] A. Kulmyrzaev, E. Dufour, Determination of lactulose and furosine in milk using front-face fluorescence spectroscopy, Lait. 82 (2002) 725-35.

[19] V. Vagenende, M. G. S. Yap, B. L. Trout, Mechanisms of Protein Stabilization and Prevention of Protein Aggregation by Glycerol, Biochemistry. 48 (46) (2009) 11084-96.

[20] H. Hamada, T. Arakawa, K. Shiraki, Effect of Additives on Protein Aggregation, Current Pharmaceutical Biotechnology. 10 (2009) 400-7.

[21] A. Ben-Naim, Theory of cold denaturation of protein, Advance in Biological Chemistry. 3 (2013) 29-39.

[22] M. Ruegg, U. Moor, B. Blanc, A calorimetric study of the thermal denaturation of whey protein in stimulated milk ultrafiltrate, Journal of Diary Research. 44(3) (1977) 509-20.

[23] The nature of biological systems as revealed by thermal methods, Editor Denis Lorinczy, pp112-114, Springer publisher. 